University of Nebraska - Lincoln

DigitalCommons@University of Nebraska - Lincoln

Studies from the Zoological Laboratory: The

University of Nebraska

January 1896

\title{
The Food Supply of the Great Lakes; and Some Experiments on its Amount and Distribution
}

Henry B. Ward

University of Nebraska - Lincoln

Follow this and additional works at: https://digitalcommons.unl.edu/zoolabstud

Part of the Zoology Commons

Ward, Henry B., "The Food Supply of the Great Lakes; and Some Experiments on its Amount and Distribution" (1896). Studies from the Zoological Laboratory: The University of Nebraska. 20.

https://digitalcommons.unl.edu/zoolabstud/20

This Article is brought to you for free and open access by the Parasitology, Harold W. Manter Laboratory of at DigitalCommons@University of Nebraska - Lincoln. It has been accepted for inclusion in Studies from the Zoological Laboratory: The University of Nebraska by an authorized administrator of DigitalCommons@University of Nebraska Lincoln. 
Published in PROCEEDINGS OF THE AMERICAN MICROSCOPICAL SOCIETY, vol. 17 (1896), pp. 242-254.

Re-issued in STUDIES FROM THE ZOOLOGICAL LABORATORY

THE FOOD SUPPLY OF THE GREAT LAKES; AND SOME EXPERIMENTS ON ITS AMOUNT AND DISTRIBUTION.

Henky B. IVard, Ph. D., Lincoln, Neb.

The subject of agriculture has received for many years the closest attention of scientific workers. Not only the character of the different products, their food value for different uses and in connection with the raising of different kinds of stock; but also the value of the soil, the use of each element in it, the exact relation of each individual particle in the entire chain of biological relations from the unorganized matter to the saleable beef or pork, has received from the experiment stations of the country the most carcful study. Every one of the pests, of the enemies which threaten any agricultural product, be it plant or animal, has been the object of similar active inquiry.

There is, however, one subject of economic importance which has never received the same treatment in scientific hands. Despite the painstaking investigations of a few scientific workers and the encouragement of some official boards with limited means, aquaculture has been almost as much neglected as agriculture has been advanced, and all because continued and systematic studies of its problems have not been supported and encouraged. The incentive given by the early work of Hoy, Milner and Forbes on the Great Lakes a quarter of a century ago has not been followed up; chance has been relied upon to control the conditions in these vast inland seas, and the fundamental featurcs of the problems are as little understood to-day as when there was no drain upon the life in these waters. No farmer is so ignorant as to suppose he could scatter the seeds of a grain whose development was entirely unknown over land of which he was equally ignorant, and leaving the land could hope on his return in the fall to reap a bountiful harvest. And yet this is just what has been looked for in the case of the white-fish. To use 
the expression of Professor Reighard, published in his report as scientific expert of the Michigan Fish Commission, a year ago, the fish culturists in the Great Lakes have been endeavoring to take the young white-fish just hatched, an absolutely unknown quantity, and put. it into the water of the lakes, another equally unknown quantity, and hoped from the union of two unknowns to secure marketable white-fish. Putting the question in that way it is evident that only the good fortune of a blunder of some sort could result in practical benefit. As a matter of fact, when we examine the figures showing the results of whitefish culture, we find that while there have been poured into the waters of the lakes at different points some hundreds of millions of young fry every year, the number of white-fish caught, the supply present in the lakes, has decreased steadily year by year.

The question must be attacked from the other direction. We must find at the first something of the biological conditions in the life of the white-fish; we must be able to say something of where it goes, what it ought to do, with what enemies it has to contend, what food it needs, what temperature, what general conditions for development, before we can hope that the result of white-fish culture will be more satisfactory. The conditions of domestic economy on the land are so evident to our eycs that we hardly stop to think of them. IVe see the large plants, the grasses particularly, derive their nourishment directly from the soil, the water and the atmosphere, turning inorganic matter into organic; we see this organic material in the domestic economy of the cattle turned into beef-steak, and so the transition is direct and immediate. It goes on, as we think, before our eyes, and while the question is, naturally, more complicated than can be outlined in a sentence or two, we think that we understand it. The conditions in the Great Lakes are so utterly different that when we come to speak of them we can afford no explanation of what is the series of changes from the inorganic matter to the organic, and from that to the white-fish in this particular instance.

Without stopping to outline extensively the characteristic feat- 
ures of the lakes themselves, I will simply enumerate two or three characters which will appeal to you as peculiar. The absence of large plants, $i$. $c$., the absence of vegetation in the more popular sense of the word, is important. Shore plants are almost entirely lacking; the storms and the shifting character of the shore itself, as well as the very small area of shallow water, tend to reduce the possibilities for existence for the higher plants, such as Pluragrimitcs, Scirpus, Potamogcton and others, that grow in the littoral zonc. The Characex, water plants that are found in most or all of our shallow lakes in enormous numbers, so that for instance in Lake St. Clair the bottom may be said to be carpeted with them as thickly as a thrifty field of clover-these are found in the Great Lakes only in comparatively isolated patches.* While it is true that so far as I can find, with the cxception of a few rather scarce species of Gastropods, there is no water form that fecds directly upon these plants, still they give shelter to an cnormous number of minute forms, forms which depend upon them for protection and find on them the growth of smaller plants on which they live. The absence of these plants in the Great Lakes reduccs at once one element which is important in all other fish regions: there is ordinarily only a scanty bottom flora and fauna present.

Another source of food supply might be supposed to be the different strcams, which would bring to the lake nourishment in one form or another. But if you examine the maps you will see at once that the inflow into the Great Lakes is very small in comparison with the total volume of the lakes themselves. The conditions there are practically stable. The inflow and outflow alter the volume only by a very small per cent.** This is due, of course, to the enormous area and depth of the lakes, and Lake Michigan alone is said to contain more than one-tenth of all the fresh water on the face of the globe.

In the next place from the atmosphere comes a little inorganic

* I am speaking here of the deeper northern lakes. Of the conditions in Lake Erie I can not speak from personal experience, and of Lake Ontario I am entirely ignorant.

** Probably about one per cent yearly. 
material, and also a very small percentage in the shape of insects carrieel into the water by the wind. Together these constitute but a small fraction of the whole, not enough to make them more than secondarily important. The source of food must be sought, then, within the waters themselves. If you take a net of fine gauze, so fine that the meshes measure from .OI to .0O I of a square inch in opening, and draw this through the water, you will collect by it a mass of minute microscopic forms, forms that are known to most of you; though very varied, they are all included under the recently-coined scientific term of "plankton." The plankton includes all those minute forms of life which, floating free in the water, are unable by their own efforts to effect their distribution. In the case of the animals, their individual motion will change their position somewhat, but only by a distance, which is nothing in comparison with the size of the lake and the conflicting agencies of current and wave. Their distribution, then, is effected by winds, waves, currents or storms, $i . \epsilon$., movements of the water or of the atmosphere. They are passively distributed. They differ, hence, from the larger forms, such as the fishes, or the larger Crustacen, in that they are entirely dependent on their environment; they can not alter it at will.

Within this group of forms are found in the first place as the fundamentally important food element, the unicellular Alga, the desmids and diatoms largely, forms which are present in an enormous number of individuals, but, as our work in the lake shows, in a comparatively limited number of species and genera. Then there are the unicellular animals, the protozoons, present also in limited number of genera and species, but also in enormous numbers of individuals. Beyond these the plankton of the northern lakes shows only two forms, or groups of forms rather, the rotifers, somewhat numerous, insignificant in size, and for plankton purposes, I believe, unimportant; and finally the microscopic Crustacea, including such forms as the different genera of Daphnids, the species of Cyclopida and Calanide and other related forms in the Entomostraca. These together constitute the elementary food supply of the water. 
The unicellular plants float as it were in a nutritive fluid, the lake water containing in solution inorganic matter derived from the air, the bottom, the shore and brought into the lake by the rains or in the inflowing streams. In the presence of light these plants are capable of transforming this inorganic substance into living matter.

It is a well-known fact that chemical action proceeds most rapidly where the proportion of surface to volume is the greatest. Leuckart brought this forward prominently in connection with the biological conditions of existence among the minute organisms, to explain the extremely rapid reproduction and multiplication of these forms. Microscopic, as they are, the proportion of surface to volume is exceedingly large, beyond comparison grreater than that of larger forms. They, of all organisms are, then, capable of producing the most active chemical processes; in other words, they are capable of most rapid growth, and since with them reproduction is clearly growth beyond the limits of the individual and division into two, reproduction or multiplication goes on with extraordinary rapidity, the number that can be produced, and consequently the number that can bc consumed, in an hour, being almost if not entirely beyond cxpression in figures.

The Protozoa live upon the unicellular Algæ, the rotifers upon both Protozoa and Alga ; the Crustacea are omnivorous, subsisting upon all of the other forms, either dead or living, eating everything which falls in their way; and it is this group, the Crustacea, which forms the immediate source of fish food. The smaller forms are eaten by the fish fry directly, and are sometimes the immediate food of the larger fishes also. One instance that may be cited is the case of the lake herring, which feeds directly upon these smaller crustaceans. With one intermediate stage these forms constitute the food of the white-fish* and of the larger fish of the lake. The immediate food of the

\footnotetext{
*Under the term "white-fish" I wish to include not merely the particu. lar species known properly under that name, but also the forms called "long-jaw," "black-fin," "tullibee," etc., which are closely related specits.
} 
white-fish, as was shown by the investigations of the Michigan Fish Commission at Charlevoix, last year, consists of Mysis, Pontoporcia, several different forms of gasteropods, small Spharia, Pisidia, etc., among the lamellibranchs, and a single form of insect life, two species of Chironomus larva, which are excecdingly abundant at the bottom of the lake.

This is discussed very briefly, simply to show in outline the connection between the plankton and the white-fish. The plankton bears exactly the same relation to the lake herring that the grass does to beef steak. It bears the same relation to the whitefish, only that the relation is one step further removed. As I might say, if cats were a source of revenue, the raising of cats would depend upon the grass through the medium of the beef eaten by the cat; so the store of the white-fish depends upon the plankton through the medium of the larger forms, Mysis, Pontoporcia, ctc., which feed directly upon the plankton.

If the plankton is, then, the productive source of food supply for the lake fishes, it becomes important to know something with reference to its distribution, horizontally in area, and vertically in strata, as well as its distribution in the different seasons of the year and under different conditions of weather. The questions of distribution in different seasons, and different conditions of weather, are so great that not one year but many years of closest observation are necessary to give even an approximate idea of them. However, the distribution vertically, and to some extent horizontally, can be ascertained by more restricted investigations. The Michigan Fish Commission for two years has maintained an investigating party in the field; in I893 it was in charge of Prof. J. E. Reighard, and in I894, during his absence in Europe, I had the privilege of directing it. During the first year the work was on Lake St. Clair; the second year it was carried on at Charlevoix, Mich., which is in the Traverse Bay region, in which the white-fish is caught during the entire year.

It is possible here only to outline briefly the chief results, without going into details with reference to the methods used, which 
are given in full in the report of Prof. Reighard and in my own.*

The amount of plankton obtained has been measured and compared for different places. The first chart (Plate I.) shows the most important results, tabulated in a way to admit of ready comparison. It was customary to select points on the lake at certain distances from each other, with certain relations to shore, shallow watcr and fishing srounds; to make hauls with a vertical net at each of these places. The material obtained was carefully preserved, and later measured, in order to obtain the amount of plankton in the water strained by the nets. By calculating the amount of water filtered, and the area of the net, the amount of plankton under one square meter of surface is found, and this is used in the plate. The dotted line (D) shows the depth of water at the different stations. The total amount of plankton under one square meter of surface, as measured in cubic centimeters, is shown by the solid line $(T)$, each station being represented by a vertical line with Roman numeral. By dividing the total amount of plankton obtained by the depth of the water, it is evident that the amount per cubic meter of water is found, and this is expressed by the line (R) of relative volumes.

Two or three points are very evident on the examination of this chart. In the first place it will be seen, by comparing the line of depth with that of total volumes, that, while the latter suffers some fluctuations, it increases more rapidly than the depth, up to a certain point. $\dagger^{-}$For some distance then the line indicates no decided change, but finally, with the sharp downward turn of the line of depth at $\mathrm{X}$, it makes a prominent though less decided bend than that in the line of depth. Up to a depth of about $3^{\circ}$ meters, then, the total amount of plankton increases more rapidly than the depth, but beyond 50 meters less rapidly.

The amount per cubic meter, as represented by the line of

*Bulletin of the Michigan Fish Commission, Nos. 4 and 7.

tThe extreme fluctuation at XIX is due to the presence of foreign matter (sand) in the volume measured, and the dotted line from XVIII to $\mathrm{XX}$ represents more nearly the true course of the line of total volumes $(T)$ nfier eliminating this error. 
relative volumes $(R)$ is seen to decrease somewhat irregularly with increase in depth; still it follows closely the average, as indicated by the dotted line. In other words, the total amount of plankton in the water increases with the depth, and the average amount per cubic meter as clearly decreases at the same time.

The explanation of this appears when we come to consider the amount of plankton in the different layers or strata of the water. By hauling the net from different depths, first from two meters, then from five, twenty-five, fifty, one hundred meters and the bottom, or wherever the bottom haul might be, we are able to distinguish different artificial strata. We can then measure the amount of plankton collected from the different depths, and by subtraction are enabled to ascertain the amount that will be found in different strata. It may be said that the amount in the first two meters, the surface stratum, far exceeds in amount per cubic meter that in all the rest of the water. In other words, proportionally much the largest part of the plankton is accumulated in this surface stratum. This is shown in the accompanying chart (Plate II). The upper line (S) which crosses the chart variably shows the amount of plankton per cubic meter in the surface stratum. This amount appears to be independent of the depth, and similar charts show no apparent relation between its fluctuations and those of the line of temperature or of the time of day.

The amount of plankton per cubic meter of water contained in the three intermediate strata $(2-5 \mathrm{~m} ., 5-10 \mathrm{~m}$. , and $10-25 \mathrm{~m}$. is not far from half that in the surface stratum, and is nearly equal for the three strata. Curiously the amount in the middle stratum is a little greater than that in the upper, while the latter has even less than the lower of the three strata in some cases. They are all as distinct from the deeper strata as from the surface stratum. In fact the deeper strata $(25-50 \mathrm{~m}$., and $50 \mathrm{~m}$. bottom) possess extremely little plankton, so little that it appears as a negative quantity in some instances. This will occur in applying the method of subtractions when the total amount present in any stratum is less than the errors of the method or than 
the normal fluctuations in the amount of plankton found in the superjacent water.

With reference to the areal distribution of the plankton, it may be said that so far as can be ascertained the amount in one part of the lake is the same as the amount of plankton in any other part of the lake; not only that, but there is no great difference in the amount of plankton in the upper end of Lake Michigan and the amount of plankton taken from the western end of Lake Erie in some hauls made by Professor Reighard two years ago. In other words, the conditions of existence are so uniform throughout the lakes, and if you consider the temperatures, the light and the other conditions, you will see that this might have been expected to be the case-the conditions of life are so uniform that in the Great Lakes we find corresponding amounts of plankton in widely separated regions. The conditions of existence in the surface two meters are so similar that we find approximately the same amount in the surface two meters everywhere. But the conditions below that alter so rapidly with the lowering of the temperature, the withdrawal of the light, and the change in pressure, which are undoubtedly the three great conditions influencing them, that below the two-meter line the amount of plankton is very much less than in the upper two meters. It must not be thought, however, that this is a fixed limit; the strata are purely artificial, and the mass of life in the upper two meters may, so far as our present knowledge is concerned, be accumulated in any part of the stratum. In Lake St. Clair Reighard found that the upper one and one-half meters held the bulk of the plankton. The more exact limits of the water within which the plankton is most crowded are yet to be determined.

Finally, the distribution of the plankton is merely the sum of the distributions of its component species, and on the investigation of the latter must wait the solution of the various peculiarities in the former. I should like to call your attention here to the splendid work recently done by Birge in Lake Mendota, Wis., and Marsh in Green Lake, Wis. By such work is accumulated most valuable evidence on the biological conditions in smaller bodies of 
water. But fish culture will never attain its proper results until it receives from the hands of the people the same favors that have been extended to agriculture, the establishment of permanent and well-equipped experimental stations, where trained workers shall devote all their time and energy to the solution of its problems. The Great Lakes furnish a cheap and valuable food supply to one third of our entire population; this food supply is rapidly becoming depleted; how long must such important interests await their just recognition and adequate protection? And if properly developed who can limit the possibility of these inland seas in supplying the nation with food? 


\section{EXPLANATION OF PLATES.}

Vertical lines indicate stations, each of which is designated by a Roman numeral.

Horizontal lines denote amount or distance according to the figures on the margin.

A, hauls in Lake Michigan.

$B$, hauls in Round and Pine Lakes.

\section{PLATE I.}

D-- $-\mathrm{D}$, indicates depth of various stations.

$\mathrm{T}$ - $\mathrm{T}$, indicates total rolume of plankton in bottom hauls with vertical net.

$R-R$, indicates volume of plankton per cubic meter of water in same hauls. 
PLATE I.

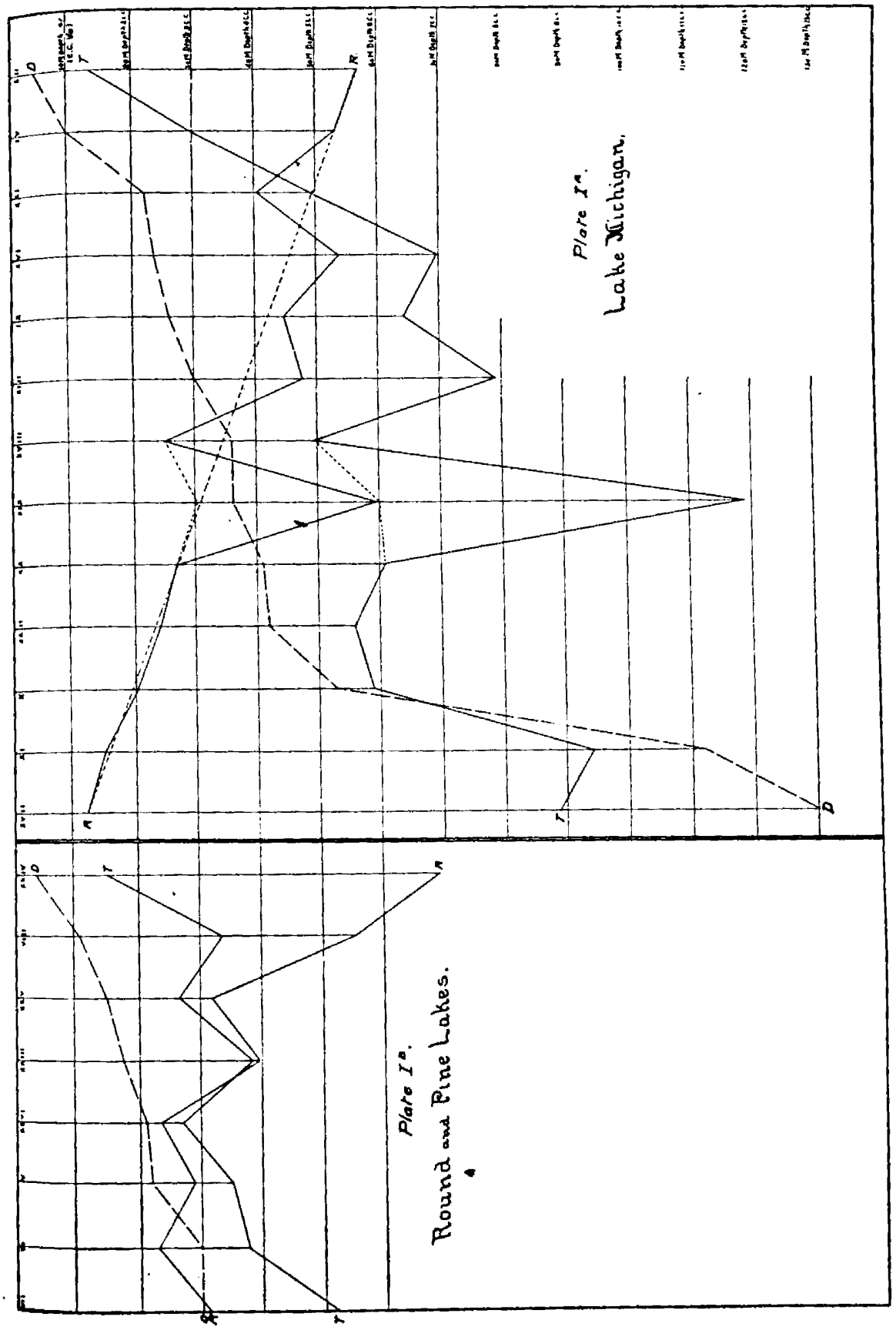


PLATE II.

$\mathrm{D}---\mathrm{D}$, as before.

$\mathrm{S}-\mathrm{S}$, amount of plankton in hauls from $2 \mathrm{~m}$. to surface.

$2-5 \mathrm{~m}$., amount of plankton in hauls from $5 \mathrm{~m}$. to $2 \mathrm{~m}$.

5-10 m., amount of plankton in hauls from $10 \mathrm{~m}$. to $5 \mathrm{~m}$.

$10-25 \mathrm{~m}$., amount of plankton in hauls from $25 \mathrm{~m}$. to $10 \mathrm{~m}$.

$25-50 \mathrm{~m}$., amount of plankton in hauls from $50 \mathrm{~m}$. to $25 \mathrm{~m}$.

$50 \mathrm{~m}$. - bottom, amount of plankton in hauls from bottom to $50 \mathrm{~m}$.

For further details see text. 
PLATE II.

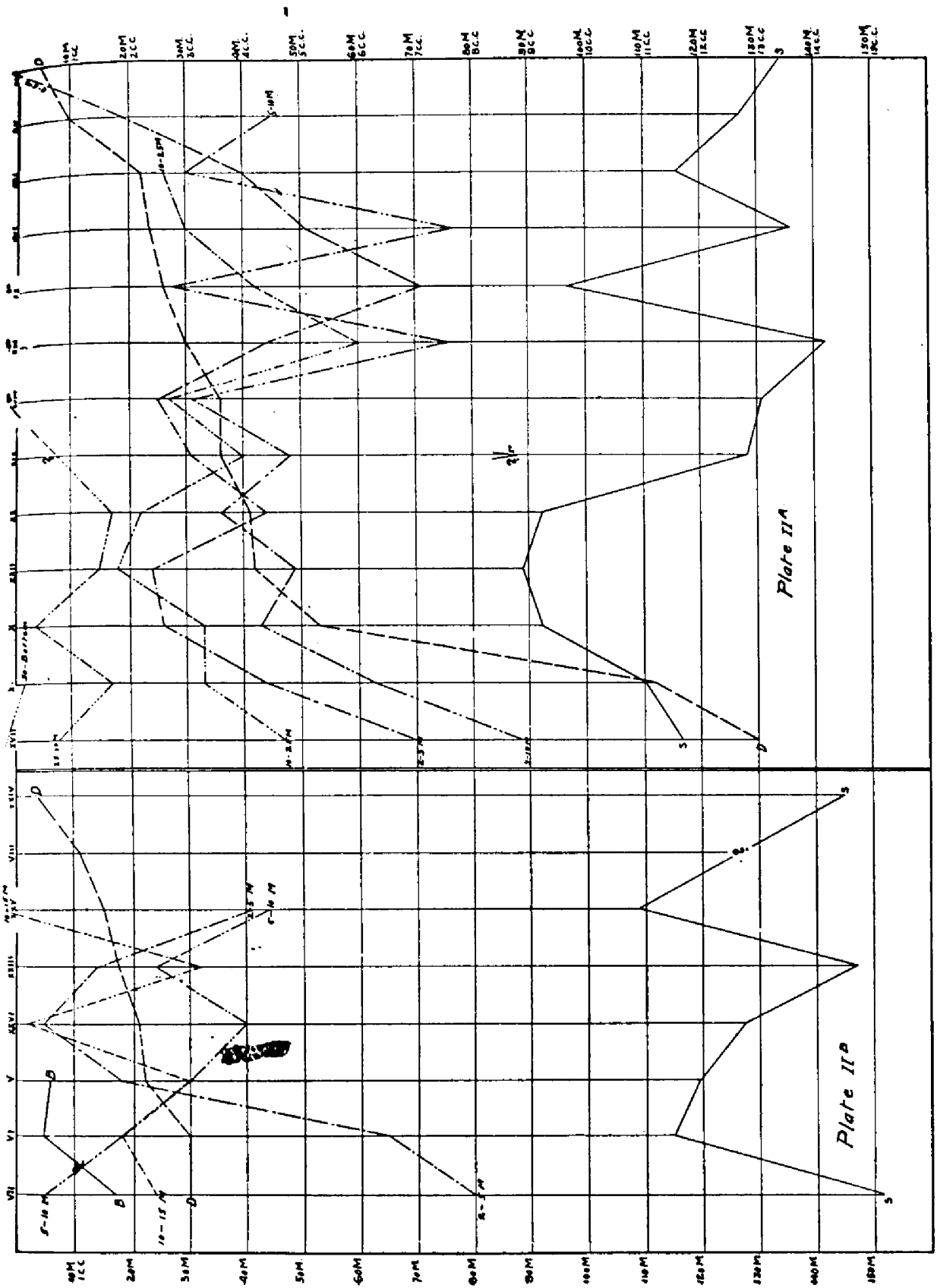

